\title{
Genome comparison of the epiphytic bacteria Erwinia billingiae and E. tasmaniensis with the pear pathogen E. pyrifoliae
}

\author{
Michael Kube*1, Alexander M Migdoll1', Isabel Gehring2,3, Katja Heitmann'1, Yvonne Mayer1', Heiner Kuhl1', \\ Florian Knaust ${ }^{1}$, Klaus Geider² and Richard Reinhardt ${ }^{1}$
}

\begin{abstract}
Background: The genus Erwinia includes plant-associated pathogenic and non-pathogenic Enterobacteria. Important pathogens such as Erwinia amylovora, the causative agent of fire blight and E. pyrifoliae causing bacterial shoot blight of pear in Asia belong to this genus. The species E. tasmaniensis and E. billingiae are epiphytic bacteria and may represent antagonists for biocontrol of fire blight. The presence of genes that are putatively involved in virulence in E. amylovora and E. pyrifoliae is of special interest for these species in consequence.

Results: Here we provide the complete genome sequences of the pathogenic E. pyrifoliae strain Ep1/96 with a size of $4.1 \mathrm{Mb}$ and of the non-pathogenic species E. billingiae strain Eb661 with a size of $5.4 \mathrm{Mb}$, de novo determined by conventional Sanger sequencing and next generation sequencing techniques. Genome comparison reveals large inversions resulting from homologous recombination events. Furthermore, comparison of deduced proteins highlights a relation of E. billingiae strain Eb661 to E. tasmaniensis strain Et1/99 and a distance to E. pyrifoliae for the overall gene content as well as for the presence of encoded proteins representing virulence factors for the pathogenic species. Pathogenicity of E. pyrifoliae is supposed to have evolved by accumulation of potential virulence factors. E. pyrifoliae carries factors for type III secretion and cell invasion. Other genes described as virulence factors for E. amylovora are involved in the production of exopolysaccharides, the utilization of plant metabolites such as sorbitol and sucrose. Some virulence-associated genes of the pathogenic species are present in E. tasmaniensis but mostly absent in $E$. billingiae.
\end{abstract}

Conclusion: The data of the genome analyses correspond to the pathogenic lifestyle of E. pyrifoliae and underlines the epiphytic localization of E. tasmaniensis and E. billingiae as a saprophyte.

\section{Background}

The genus Erwinia comprises essentially plant-associated bacteria. Two species, Erwinia amylovora and Erwinia pyrifoliae, are connected with "pome fruit" diseases, fire blight of apple, pear and some ornamentals and Asian pear blight, respectively [1-3]. Other species were isolated from plant surfaces such as Erwinia billingiae and Erwinia tasmaniensis. Due to their epiphytic occurrence, they can compete with growth and distribution of $E$. amylovora on flowers and may be applied as antagonists for control of fire blight [4]. Such bacteria have the poten-

* Correspondence: kube@molgen.mpg.de

${ }^{1}$ Max Planck Institute for Molecular Genetics, htpt group, Ihnestr. 63, D-14195 Berlin, Germany

Full list of author information is available at the end of the article tial to reduce the use of antibiotics in agriculture for control of the disease. Accumulation of streptomycin resistant strains in pome fruit growing regions in the United States emphasizes the need of new strategies to reduce economical losses of more than $\$ 100$ million per year for the United States resulting from fire blight [5-10]. In the course of description of pear pathogenic E. pyrifoliae strains, isolated in Korea, it became evident that they are related to E. amylovora, but distinct for several taxonomic criteria [11]. A pathogen associated with bacterial shoot blight of pear (BSBP) in Japan was also classified as E. pyrifoliae [12]. Strain Ep1/96 from Korea is assumed to be a representative for E. pyrifoliae and the features are also valid for the strains from Japan. 
In dendrograms from $16 \mathrm{~S}$ rRNA sequences and in alignments of parts from the house keeping genes gpd and recA, E. pyrifoliae is related to E. amylovora, less to $E$. tasmaniensis and in more distance to E. billingiae [12].

Several properties of these species can explain their interactions with plants. Pathogens as well as epiphytic bacteria are dependent on the availability of carbohydrates to metabolize them as an energy source. Plants synthesize and transport high levels of sucrose as a main product of photosynthesis. E. amylovora, the fire blight pathogen, is specialized on rosaceous plants, which typically also produce sorbitol. Mutants of E. amylovora in the sucrose and in the sorbitol metabolism are nonpathogenic $[13,14]$. Surprisingly, E. tasmaniensis lacks the $\mathrm{srl}$-operon and is unable to metabolize sorbitol, although the epiphytes were isolated from the apple and pear flora $[15,16]$. E. billingiae was isolated from a similar environment, initially designated as "white Erwinia herbicola" and later classified as a novel species $[17,18]$. These bacteria are also detected in necrotic plant tissue from trees with fire blight (Geider et al., unpublished), but do not share important properties with E. amylovora [4]. These include the inability of $E$. billingiae to cause a hypersensitive response (HR) on tobacco leaves, a lack of levan synthesis with a general deficiency to metabolize sucrose [4]. A deficiency in levan formation was also observed for $E$. pyrifoliae [1]. On the other hand, destruction of the host plant tissue, indicated by HR on non-host plants, is an important pathogenicity factor of E. amylovora and was also described for E. pyrifoliae $[1,19,20]$.

Another important pathogenicity factor of $E$. amylovora and $E$. pyrifoliae is the formation of capsular exopolysaccharide (EPS). Gene clusters encoding functions for amylovoran synthesis of E. amylovora and pyrifolan synthesis of $E$. pyrifoliae have been described and mutants created in these genes by transposon and by site directed mutagenesis, which lost virulence [21,22]. Other virulence factors of E. amylovora were described to include iron uptake, or defects in amino acid or nucleotide metabolism [23].

Therefore it was of special interest to show, if factors necessary for invasion can be identified in the genome of E. pyrifoliae and if their absence in the genome of $E$. billingiae and E. tasmaniensis can describe their epiphytic occurrence in plant surfaces.

We determined the complete genome of the pearpathogen E. pyrifoliae strain Ep1/96, which is related to $E$. amylovora and of the non-pathogenic E. billingiae strain Eb661 [11,24]. A mixed strategy of pyrosequencing and traditional Sanger sequencing was used to determine both new genome sequences. These data together with the previously published genome sequence of E. tasmaniensis provide databases for comparative analysis of virulence factors.

\section{Results and Discussion}

\section{Genome composition and architecture of Erwinia billingiae} strain Eb661, E. tasmaniensis strain Et1/99 and E. pyrifoliae strain Ep1/96

The genomes of E. billingiae strain Eb661, E. tasmaniensis strain Et1/99 and E. pyrifoliae strain Ep1/96 contain one circular chromosome with a size of $5.1 \mathrm{Mb}$ for strain Eb661, and 4.0 Mb for strain Ep1/96 down to 3.9 Mb for strain Et1/99 [15]. The number of corresponding predicted proteins ranges from 4,587 to 3,427 (Table 1). The distant position of E. billingiae strain Eb661 is indicated by the general genome data and corresponds to the phylogenetic position on a different branch in contrast to the other three genomes [12,24]. This classification into two groups is also supported by the estimated numbers of shared genes for the chromosomes of the strains Ep1/96, Et1/99 and Eb661 (6,883 out of 11,659 proteins in total) (Figure 1). The highest amount of unique proteins is present for strain Eb661 with 2,037 proteins (2,065 including paralogs etc.) corresponding to the enlarged chromosome size. This portion encompassing $4 \%$ of the deduced protein set encodes a wide additional metabolic repertoire and associated transporters. In contrast, the portion of estimated unique genes for the pathogenic strain Ep1/ 96 is 785 (897 including paralogs etc.) corresponding to approx. $25 \%$ of the proteins encoded on the chromosome.

The number of 7 rRNA operons is constant within the chromosomes, but the presence of one unusual rRNA operon with a $16 \mathrm{~S}-23 \mathrm{~S}-5 \mathrm{~S}-5 \mathrm{~S}$ organization is limited to

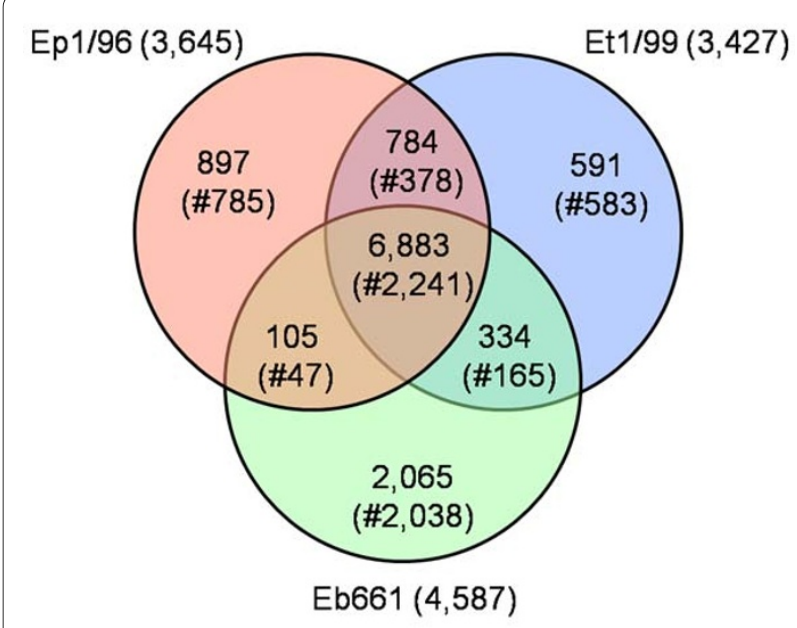

Figure 1 Venn diagram for the deduced proteins of $E$. pyrifoliae strain Ep1/96, E. tasmaniensis strain Et1/99 and E. billingiae strain Eb661. Values were calculated by BLASTCLUST using an identity of $>60 \%$, an alignment length of $>70 \%$ and an e-value of 1 e- 6 as cut-off. The number of proteins per chromosome is given. The number of clusters (\#) is given in brackets representing the non-redundant proteincoding genes per intersection. The overlapping sections indicate shared numbers of proteins. The total number of all deduced proteins of these three species is 11,659 . 
Table 1: Chromosome features for the genomes of $E$. pyrifoliae strain Ep1/96, E. tasmaniensis strain Et1/99 and E. billingiae strain Eb661.

\begin{tabular}{|c|c|c|c|}
\hline Strain & Ep1/96 & Et1/99 & Eb661 \\
\hline Size (bp) & $4,026,322$ & $3,883,467$ & $5,100,168$ \\
\hline Seq. coverage & $34^{* 1}$ & 11 & $19^{* 2}$ \\
\hline $\mathrm{G}+\mathrm{C}$ content $(\%)$ & 53.4 & 53.7 & 55.2 \\
\hline Protein coding (\%) & 84.9 & 85.0 & 87.7 \\
\hline Coding sequences & 3,645 & 3,427 & 4,587 \\
\hline Average size (bp) & 938 & 964 & 975 \\
\hline $\mathrm{G}+\mathrm{C}$ content $(\%)$ & 54.6 & 54.9 & 56.3 \\
\hline Assigned function & 2,846 & 2,676 & 3,768 \\
\hline $\begin{array}{l}\text { Conserved } \\
\text { uncharacterized }\end{array}$ & 549 & 389 & 515 \\
\hline Uncharacterized & 250 & 362 & 304 \\
\hline Transposases & 90 & 25 & 10 \\
\hline assigned as pseudo & 57 & 57 & 13 \\
\hline rRNA operons & 7 & 7 & 7 \\
\hline tRNAs & 75 & 81 & 77 \\
\hline $\begin{array}{l}\text { extrachromosomal } \\
\text { elements }\end{array}$ & 4 & 5 & 2 \\
\hline \multicolumn{4}{|c|}{$\begin{array}{l}\text { Sequencing coverage was reached by a 9fold Sanger sequencing and } \\
\text { a } 25 \text { fold coverage with GS20 data for strain Ep } 1 / 96 \text { and by a } 11 \text { fold } \\
\text { Sanger sequencing and a } 8 \text { fold coverage with GS FLX data for strain } \\
\text { Eb661. } \\
\text { rRNA operons show } 16 \mathrm{~S}-23 \mathrm{~S}-5 \mathrm{~S} \text { order, except one copy within the } \\
\text { chromosome of the strains Ep } 1 / 96 \text {, Ea273 and Et } 1 / 99 \text { with the } \\
\text { unusual } 16 \mathrm{~S}-23 \mathrm{~S}-5 \mathrm{~S}-5 \mathrm{~S} \text { order organization. The } 16 \mathrm{~S}-23 \mathrm{~S}-5 \mathrm{~S}-5 \mathrm{~S} \\
\text { operon is missing in strain Eb661, which belongs to a different } \\
\text { phylogenetic branch. }\end{array}$} \\
\hline
\end{tabular}

the genomes of strains Ep1/96 and Et1/99. This could provide a genetic marker for these species within the genus Erwinia. The occurrence of the unusual 16S-23S5S-5 S organization within the chromosome is interpreted as the result of a chromosomal recombination event. Large inversions and translocations have occurred frequently during evolution in the genus Erwinia (Figure
2). The present conserved synteny between the three genomes is disrupted by large inversions, which indicates two different types of organization. One type is shared by strain Ep1/96 and Et1/99 as well as a second one which is shared by strain Eb661 and strain Ea273 (data not shown). These re-arrangements are thought to be driven by homologous recombination, which often occurs at the rRNA operons [25]. The importance of rRNA operons for these events could be confirmed by the comparison of the chromosomes of strain Eb661 and Et1/99 for the centered inversion, which is suggested to be responsible for the duplication of the 5S-rRNA gene. The comparison of the chromosomes of strain Et1/99 and Ep1/96 indicates the stability of this re-arrangement. Several other translocations and inversions are present especially within two regions not neighbouring to rRNA operons.

However, Figure 2 also illustrates that the larger chromosome size of E. billingiae strain Eb661 is mainly based on the presence of single genes scattered over the whole genome and not on the transfer of large gene clusters. The minor influence of phage integrations was estimated by the prediction of integrated regions (258 $\mathrm{kb}$ for strain Eb661, $177 \mathrm{~kb}$ for strain Et1/99 and $261 \mathrm{~kb}$ for strain Ep1/ 96) and of gene duplication corresponding to the number of potential paralogs (76 for strain Eb661, 57 for strain Et1/99 and 223 for strain Ep1/96). Cumulative GC skew analyses support the weak modulations of the chromosomes by these events by its regular run (Additional file $1)$.

The exchange of genetic material mainly depends on the presence of extrachromosomal elements. The number of plasmids ranges from two for Eb661 to five in strain Et1/99 (Table 2). A deviating GC content compared to the chromosome suggests an unrelated origin for pET35 and pET49. Several plasmids in the genus Erwinia show the potential for a conjugal transfer such as pEB170 of E. billingiae strain Eb661, the plasmids pET35 (CU468130), pET45 (CU468132), pET46 (CU468133), pET49 (CU468131) of E. tasmaniensis strain Et1/99 and pEL60 of E. amylovora strain Leb66 (AY422214), an untypical isolate from Lebanon. Plasmids pEp05 and pEt46 carry mob genes and may contain an oriT to be mobilized by Tra proteins of other plasmids. The species E. amylovora, E. pyrifoliae, and E. tasmaniensis share thiO (glycine oxidase), thiS (sulfur carrier protein), thiG (thiazole synthase) and thiF (adenylyl transferase) in conserved order. These genes are located on plasmids of $E$. pyrifoliae and E. amylovora and on the chromosome of $E$. tasmaniensis. A potential gene flow is indicated by the high identities between the sequences on the nucleotide level and the amino acid level of at least $87 \%$ (Figure 3). E. amylovora genes for thiamine metabolism are located on plasmid pEA29. Plasmidfree strains of E. amylovora show reduced virulence and reduced growth in minimal 


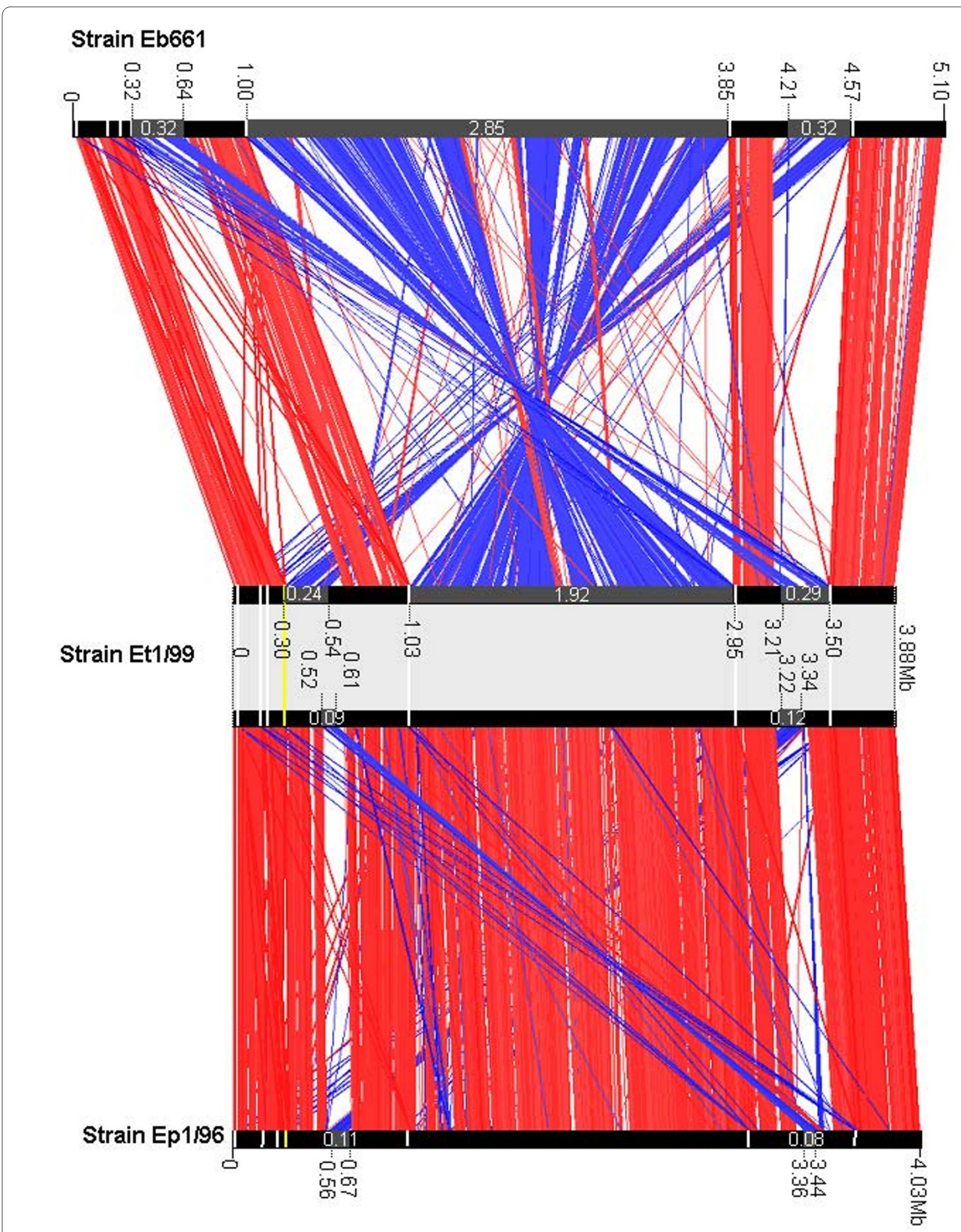

Figure 2 Chromosome organization of strain Eb661 vs. Et1/99 vs. Ep1/96. Chromosomes were compared using ACT. Red lines connect homologous regions present in the same orientation while the blue lines connect regions of inverted orientation. Black bars symbolize chromosomes. Localization of the rRNA operons is indicated by white (16S-23S-5 S rRNA organization) and yellow bars (16S-23S-5S-5 S rRNA organization). Translocated and inverted regions are highlighted in grey and the positions on the chromosomes are provided. The estimated size of these regions, which were modulated by several re-arrangements, is noted in megabases. 


\section{Et1/99}

CU468135

860000

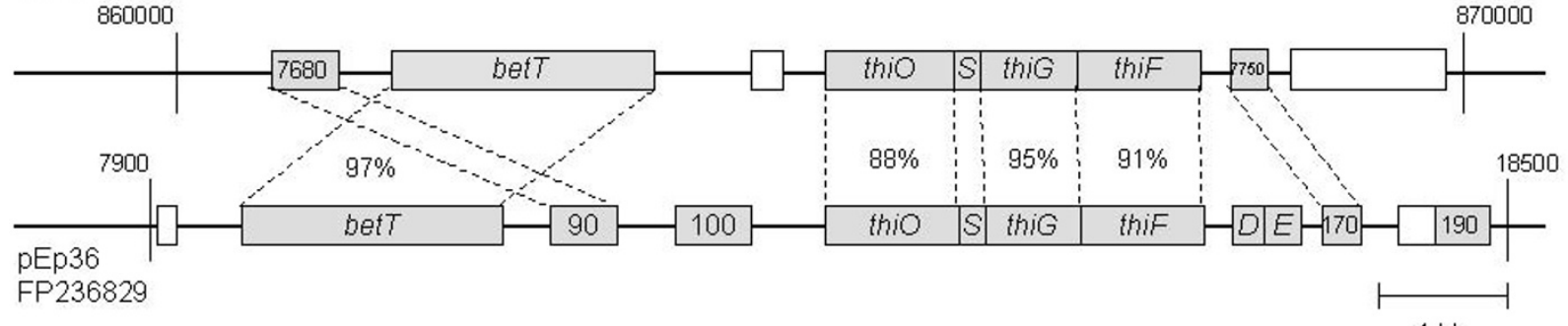

$1 \mathrm{~kb}$

Figure 3 Alignment of genes involved in thiamine biosynthesis (thiOSGF), a toxin-antitoxin system (stbDE) and a choline transporter (betT) for E. tasmaniensis, and E. pyrifoliae. The maps show corresponding parts from the chromosome of E. tasmaniensis strain Et1/99 and from plasmid pEP36 of E. pyrifoliae strain Ep1/96. BlastP results (percentage identity) are shown for related genes (grey boxes). Labels indicating the locus tag number are given within the grey boxes, if no gene name is assigned. White boxes indicate genes without similarity. The proteins for thiamine biosynthesis (thi) and the flanking regions are highly related and the genes are in conserved order. The stbD and stbE genes of pEp36 encode for a toxin-antitoxin system. A comparison for genes in this region was done before for the E. amylovora plasmid pEA29, the E. pyrifoliae plasmid pEP36 and plasmid pEJ30 from the Japanese E. pyrifoliae strain Ejp557 [89]. Locus tags of the genes are abbreviated for this overview.

medium without thiamine [26,27]. The choline transporter protein BetT is encoded in all three species and may help to protect bacteria against osmotic stress [28]. We detected homologies for $s t b D$ and $s t b E$ in the sequences of pEp36 but not for E. tasmaniensis strain Et1/99. StbD and StbE are plasmid stability proteins and code for a toxin-antitoxin system, which is widespread throughout pathogenic bacteria [29].

Pathogenicity of several Erwinia species is probably based on a large set of modules (Table 3).

We focussed the analyses on the genetic environment encoded within the genomes with respect to secretion, production of exopolysaccarides, sorbitol and sucrose metabolism as well as on the presence of miscellaneous genes with potential impact to the virulence for the pathogenic erwinias.

\section{Secretion systems}

The ability to secrete effector proteins and to colonize host plant tissue represents very important features. Differences in chromosome content were also identified by mapping the deduced proteins from the non-pathogenic strains on the chromosome of E. pyrifoliae strain Ep1/96 as well as by one by one comparison (Additional file 2, Figure S2A-E; Additional file 3). The data for several combinations are arranged in Additional file 2 and several secretion systems are classified in Additional file 3 for their presence or absence in the investigated genomes.

Common secretion systems of the Enterobacteriaceae such as the $s e c$-independent (Type 1) and sec-dependent (Type 2) secretion systems have been identified in Erwinia species that fulfil vital functions, e.g. export of extracellular proteins for nutrient acquisition [30]. Among them, one of the best studied are the genetically and structurally conserved type III secretion systems (T3SSs), which were found to be crucial for delivery of proteins acting as pathogenicity factors into the extracellular space or the cytoplasm [31,32]. Target cells and secreted proteins are of broad range and host-specific.

The primary T3SS in Erwinia species is composed of the $h r p / h r c$-gene-cluster and two flanking regions (Hrp elicitors and effectors [HEE] and Hrp-associated enzymes [HAE]), which contain effector proteins and enzymes involved in systemic virulence [15,33]. Like in E. amylovora this assembly could also be identified in the pathogenic E. pyrifoliae strain Ep1/96, and clearly marks a difference to the system of the non-pathogenic $E$. tasmaniensis strain Et1/99 without the HAE region and $E$. billingiae strain Eb661, which contains no homologs to a T3SS [15]. Nevertheless, the hrp/hrc-clusters of E. pyrifoliae and E. tasmaniensis show almost conserved synteny. Slight differences are orfU1 (Acc. No. AAD24685) and orfU2 (Acc. No. AAD24686) of E. amylovora with similarity to genes coding for hypothetical proteins in Helicobacter pylori [33]. The products of those CDS may represent specific components of the E. amylovora T3SS.

A second gene cluster similar to the HAE region could be identified in E. pyrifoliae. The two genes $h s v A$ and $h s v C$ show a high similarity on amino acid level of $86 \%$ and $66 \%$, respectively, to their counterparts in the hrp/ $h r c$-T3SS. However, a corresponding $h s v B$-gene was not found in this cluster but a sequence coding for a putative capsular exopolysaccharide synthesis protein.

An incomplete T3SS similar to the Salmonella pathogenicity island 1 (SPI-1) and also found in the insect endosymbiont Sodalis glossinidus, may have a distinct function in Erwinia species [15,34]. This region, spanning about $20 \mathrm{kbp}$ in E. pyrifoliae and E. tasmaniensis, con- 
Table 2: General features of the determined extrachromosomal elements of $E$. pyrifoliae strain Ep1/96, E. tasmaniensis strain Et1/99 and E. billingiae strain Eb661.

\begin{tabular}{|c|c|c|c|c|c|c|c|c|c|c|c|}
\hline Strain & Ep1/96 & & & & Et1/99 & & & & & Eb661 & \\
\hline Plasmid tag & pEp2.6 & pEp03 & pEp05 & pEp36 & pEt09 & pEt35 & pEt45 & pEt46 & pEt49 & pEb102 & pEb170 \\
\hline Size (bp) & 2,590 & 3,070 & 4,955 & 35,909 & 9,299 & 35,494 & 44,694 & 46,159 & 48,751 & 102,323 & 169,778 \\
\hline Protein coding (\%) & 66.6 & 58.9 & 77.3 & 71.9 & 87.9 & 86.5 & 87.0 & 63.5 & 83.9 & 85.4 & 78.7 \\
\hline Coding sequences & 6 & 4 & 5 & 37 & 7 & 42 & 46 & 39 & 61 & 114 & 220 \\
\hline $\mathrm{G}+\mathrm{C}$ content $(\%)$ & 43.9 & 47.0 & 52.2 & 52.7 & 47.2 & 40.1 & 51.8 & 49.5 & 43.6 & 53.0 & 54.1 \\
\hline Assigned function & 1 & 2 & 4 & 26 & 6 & 23 & 29 & 25 & 35 & 54 & 111 \\
\hline Conserved uncharacterized & 1 & 2 & 1 & 7 & 1 & 3 & 1 & 5 & 5 & 40 & 15 \\
\hline Uncharacterized & 4 & - & - & 4 & - & 16 & 16 & 9 & 21 & 20 & 94 \\
\hline Transposase(s) & - & - & - & 7 & - & - & - & 2 & - & 1 & 6 \\
\hline
\end{tabular}

tains most of the invasion- (invFGEABC), surface presentation of antigens (spaOPQRS) and invasins with the associated chaperone-genes $(\operatorname{sic} A, \operatorname{sip} B, \operatorname{sip} D)$ as well as those encoding the needle complex (prgHIJK, orgA). However, three CDS for conserved hypothetical proteins were found replacing $\operatorname{sip} C$, an essential invasion gene and invIJ, encoding putative effectors [35,36]. Furthermore, the genes $\operatorname{sip} A, i a c P, \operatorname{sicB}, \operatorname{sptP}$, iagB, hilA, $\operatorname{org} B C$ and hilC, which constitute mainly regulatory components, are lacking. The gene content and order is highly conserved between E. pyrifoliae and E. tasmaniensis. A similar island was not found in E. billingiae. However, it remains unclear, if this T3SS is operative because of the incompleteness in comparison to the SPI-1 and the replaced genes. Recent results from pathogenicity tests on immature pears with SPI-1-like mutants of E. amylovora indicate that it is not essential for pathogenicity [37]. Even for Salmonella typhimurium it was shown, that only the initial infection stages are affected in mutants while they remain pathogenic when applied by different routes [38].

Only few CDS for putative effector proteins could be identified in the erwinias. Most of those proteins are thought to affect or to be secreted by the T3SS. The suggested effector SrfC of Pectobacterium carotovorum subsp. atrosepticum is also thought to be exported by T3SS [39]. E. billingiae carries the $\operatorname{srfABC}$ gene cluster like the other three erwinias, but is lacking the instrumentation for a T3SS. The function of SrfC remains unclear, in consequence.

Both pathogenic erwinias possess coding sequences for the SopA protein, which has been characterized as an effector-like protein in Salmonella influencing the inflammatory response of mammalian hosts [40]. This protein is translocated via the Salmonella T3SS on the SPI-1 into eukaryotic cells and seems to be necessary for full virulence [41]. Since a similar T3SS has been identified in the pathogenic erwinias, one could assume that the SopA effector has a particular role in pathogenicity of those bacteria in plants. It could influence proteins in the plant cell to alter defence response to bacterial invasion. Another putatively SPI-1 dependent system found in the four Erwinia species is composed of the small operon $\operatorname{srf} A B C$, which seems to be regulated by SPI- 1 activation [42]. Repression is accomplished by RcsB and PhoP, 
Table 3: Genetic elements with potential impact to virulence of pathogenic erwinias were summarized and the presence of the key genes is indicated for the analysed genomes (for details please see Additional file 33).

\begin{tabular}{|c|c|c|c|c|c|}
\hline Functional context & Description & Key genes & Ep1/96 & Et1/99 & Eb661 \\
\hline \multicolumn{6}{|l|}{$\begin{array}{l}\text { Secretion systems and } \\
\text { effectors }\end{array}$} \\
\hline \multirow[t]{3}{*}{ hrp/hsv/dsp cluster (T3SS) } & Hrp-associated enzymes (HAE) & hrpK, hsvABC & + & - & - \\
\hline & Hrp/hrc secretion/translocation pathway & $\begin{array}{l}\text { hrcUTSRQ, hrpPO, hrcN; hrpQIJLXYSAB; } \\
\text { hrcJ, hrpDEFG, hrcC, hrpTV }\end{array}$ & + & + & - \\
\hline & Hrp elicitor/effector region (HEE) & $h r p N$, orfABC, hrpW, dspEF & + & + & - \\
\hline \multirow[t]{4}{*}{ Salmonella SPI-1-like T3SS } & Invasion proteins & invHFGEABCIJ & $(+)$ & $(+)$ & - \\
\hline & Surface presentation of antigens (SPA) & spaOPQRST & $(+)$ & $(+)$ & - \\
\hline & Cell invasion proteins & $\operatorname{sic} A, \operatorname{sip} B C D A$, sptP, prgHIJK, orgA & $(+)$ & $(+)$ & - \\
\hline & Invasion plasmid antigen (IPA) & ipaBCDA & - & - & - \\
\hline T6SS & T6S proteins and effectors & various & $+^{*}$ & $+^{*}$ & $+^{*}$ \\
\hline $\begin{array}{l}\text { Effector and virulence } \\
\text { associated }\end{array}$ & putative operon involved in virulence & $\operatorname{srf} A B C$ & + & + & + \\
\hline \multirow{4}{*}{ proteins } & Maintenance of virulence plasmid & $m v p T$ & + & + & - \\
\hline & $\begin{array}{l}\text { Virulence protein; regulator for acidic stress; } \\
\text { integral membrane protein, outer membrane } \\
\text { protein }\end{array}$ & $m s g A, p h o P Q, m v i N$, ompX & + & + & + \\
\hline & Outer membrane invasion protein & pagc & + & - & + \\
\hline & Virulence associated protein & virk & - & + & + \\
\hline
\end{tabular}

\section{Metabolism}

Capsular polysaccharide Capsular polysaccharide- biosynthesis systems
amsGHIABCDEFKL, galFE/ cPsGHIABCDEFKL, galFE

Putative cps biosynthesis system $y m c A B C$ $r C S A, r C s B, r C s C, r C S F$ Isc $r \mid s A, r l s B, r l s C$ 
Table 3: Genetic elements with potential impact to virulence of pathogenic erwinias were summarized and the presence of the key genes is indicated for the analysed genomes (for details please see Additional file 33). (Continued)

\begin{tabular}{|c|c|c|c|c|c|}
\hline Sorbitol-Operon & Sorbitol uptake, metabolization & srlAEBDMR & + & - & + \\
\hline Sucrose-Operon & Sucrose uptake, metabolization & scrKYABR & + & + & - \\
\hline $\begin{array}{l}\text { Non-ribosomal peptide } \\
\text { synth. }\end{array}$ & Suggested phytotoxin & eppT & + & - & - \\
\hline \multicolumn{6}{|l|}{$\begin{array}{l}\text { Adhesion \& extracellular } \\
\text { factors }\end{array}$} \\
\hline \multirow[t]{3}{*}{ Cell-influencing factors } & Necrosis factors & $c n f 1, c n f 2$ & + & + & - \\
\hline & Proteases & $p t r A, p t r B$ & + & + & + \\
\hline & Siderophores & foxR, dfoA, alcA & + & + & $(+)$ \\
\hline
\end{tabular}

The presence is weighted by three criteria: "+" completely present, "(+)" present in parts and "-" absent. An extended gene content by the presence of additional genes is marked by "**".

whose coding sequences could be identified in the erwinias. For several effectors the SPI-1 related T3SS may has a special function, which is different to the hrp/hrc-T3SS but probably not essential for virulence because it is also present in the non-pathogenic species E. tasmaniensis. This would be in accordance to rececently published results on SPI-1 mutants of E. amylovora [37].

The gene virK, which is secreted by the second Salmonella T3SS found on the pathogenicity island 2 (SPI-2) and regulated by the phoPQ-genes, is a pathogenicity factor of Salmonella sp. [43]. A coding sequence for VirK was identified in E. tasmaniensis and E. billingiae but not in the pathogenic erwinias. A possible reason could be the missing secretion system for this protein, which led to the loss of the gene in the process of specialization. The T3SS share a wide homology that could support secretion by the other systems found in the Erwinia species [30]. A simple protein export machinery is built by the Type $\mathrm{V}$ secretion system (T5SS), which is found in various bacteria [44]. The main domains, a leader sequence and an extracellular effector domain, and an outer membrane export channel, are sometimes encoded on one sequence and constitute one protein. Because of the self-assembly and -export they were termed autotransporters. Another strategy, dubbed two-partner secretion, is characterized by separate expression of leader-effector protein and the leader-channel protein. Most effector proteins are involved in adherence, invasion and degradation [44]. The non-pathogenic E. billingiae is the only species where we identified genes for corresponding autotransporters (EbC_25980, EbC_37340). They show similarities to the AidA domain family, which is mainly present in enteropathogenic bacteria, and pertactin, an autotransporter found in Bordetella sp., respectively. The primary role of the afore mentioned proteins is adherence to target structures. It may be possible that they substitute the function of missing fimbrial parts found in the other Erwinia species, a difference to strains Ep1/96 and Et1/ 99.

An emerging class of secretion systems, possibly related with pathogenicity, is the recently identified Type VI secretion system (T6SS) in Gram-negative bacteria [45]. Analyses revealed one large (EpC_06160-EpC_06400, vgrG) and one small cluster (EpC_19520-EpC_19550) in E. pyrifoliae. Both clusters are present in E. tasmaniensis and E. billingiae, but show variations in gene content (Additional file 4). Most of the still uncharacterized genes are conserved within the clusters. Functions were assigned for the putative regulator Fha (involved in phosphorylation), the membrane associated proteins such as Lip (outer membrane lipoprotein), IcmF and DotU (inner membrane proteins), ClpV (ATPase) and Hcp and VgrG $[46,47]$. The proteins Hcp and VgrG are secreted, Hcp building a tube-like structure for effector delivery, while VgrG may be an effector-activator or an effector itself [45]. One CDS, found in E. pyrifoliae (EpC_06280) and E. billingiae (EbC_05860), of the larger cluster codes for a putative exported protein, which shows similarities of 50 $65 \%$ to a protein of other plant-pathogenic bacteria such as Pectobacterium atrosepticum (syn. Erwinia carotovora ssp. atroseptica) and Pseudomonas syringae pv. tomato. In case this exported protein has an effector function, it would match the previous results, that E. tasmaniensis is missing many other effector proteins [15]. Whether the 
secretion systems have an influence on pathogenicity is undiscernible so far, since only a rudimentary instrumentation was found in E. amylovora. Plant invasion, which was not confirmed for E. tasmaniensis, may be an important requirement for the function (i.e. translocation of proteins into dedicated host cells).

For the T6SS essential gene content, function assignment and structural determination is not well advanced. Most information exist for animal pathogens, but also plant pathogens may use T6SS [48]. Nevertheless, the intrinsic role of the T6SS beside T3SS and/or T4SS has yet to be determined.

\section{Genetics of EPS synthesis by E. pyrifoliae and E. billingiae}

Several metabolic factors are considered to play an important role for causing disease in Erwinia-infected plants including synthesis of exopolysaccharides (EPS) i.e. amylovoran or related products and levan production as well as metabolism of sorbitol and sucrose [49].

The capsular EPS of E. amylovora is amylovoran, which apparently modulates recognition of the bacteria by plant defense mechanisms and is a main pathogenicity factor [50]. The gene cluster for EPS-synthesis of pyrifolan by $E$. pyrifoliae also consists of 12 CDS (Additional file 3) with two adjacent genes for precursor synthesis. The encoded proteins are at least $85 \%$ similar and have a conserved order for E. pyrifoliae and E. amylovora. The repeating units of amylovoran and pyrifolan have the same sugar composition and identical linkages except a missing second side chain of glucose for pyrifolan [22].

No EPS has been identified so far for E. tasmaniensis, but there is a gene cluster for synthesis of capsular polysaccharide on the chromosome [15]. E. billingiae possesses similar genes but produces an EPS. In alignments of Cps proteins from E. pyrifoliae and E. billingiae, CpsF (WceF) have a remarkable divergence, which may indicate specific functions for processing and assembly of the repeating units of capsular EPS for both species.

E. amylovora produces another EPS, levan, which serves as quickly generated shield against recognition by plant defence reactions [51]. The secreted levansucrase, encoded by $l s c$, cleaves sucrose into glucose and fructose, which is subsequently polymerized to levan [52]. Levan is not strictly necessary for virulence of E. amylovora [51]. Also the non-pathogenic E. tasmaniensis possesses an $l s c$ gene and produces levan [15]. E. pyrifoliae lacks the $l s c$ gene, but an orf (EpC_17920) coding for a protein similar to levanase was identified [22]. Levanase belongs to the $\beta$ $D$-fructofuranosidases and can also cleave inulin and sucrose [53]. Therefore, the enzyme could provide nutrients by cleavage of fructans in plant tissue, and may degrade levan from synthesizing bacteria, if it is secreted by E. pyrifoliae.

\section{Sorbitol and sucrose metabolism}

A dominant carbohydrate in rosaceous plants is the transport sugar alcohol sorbitol. In case of E. amylovora the proteins for its metabolization are encoded by the genes $\operatorname{sr} l A E B D M R$, which could also be identified for $E$. pyrifoliae and $E$. billingiae but not in the genome of $E$. tasmaniensis [13,15]. Virulence assays of E. amylovora srl-mutants showed reduced symptoms on apple seedlings but only weak effects on pear slices due to their low content of sorbitol. The content of sorbitol is high in leaves and in transport tissue, and its amount varies during plant development [54].

Sucrose is another important transport sugar in plants. Mutants of E. amylovora in the scr operon are non-virulent [14]. The disaccharide is actively transported into the cells and subsequently cleaved. Besides the repressor gene $s c r R$, four genes encoding steps in sucrose metabolism are present in E. amylovora, E. pyrifoliae and E. tasmaniensis. The genes scrKYABR are located in an operon for these three species, but E. tasmaniensis carries a second copy of $\operatorname{scr} A B$ [15]. Alignments with MAUVE of the srl regions of E. pyrifoliae and E. billingiae as well as the scr region of E. pyrifoliae and E. tasmaniensis show a remarkable similarity for these gene clusters including the second $s c r A B$ copy in the genome of E. tasmaniensis (Figure 4) [55]. This region does not completely comprise the $\operatorname{scr} A B$ gene cluster, but is extended to $400 \mathrm{bp}$ downstream of $s c r B$ and to a partial similarity at $1000 \mathrm{bp}$ upstream of $s c r A$.

An interesting feature of E. billingiae is its possible ability to metabolize xylitol. This sugar alcohol is widely distributed in nature and can interfere with bacterial activities [56]. E. billingiae may degrade xylitol to avoid interference with its growth and to use it as a carbon source despite its low nutritional value. A similar gene is missing in the genomes of E. pyrifoliae strain Ep1/96 and the E. tasmaniensis strain Et1/99. On the other hand, E. tasmaniensis strain Et2/99 can grow with xylitol as carbon source [16].

\section{Miscellaneous determinants with potential impact to virulence of pathogenic erwinias}

A striking difference between the pathogenic species $E$. pyrifoliae and the non-pathogenic E. tasmaniensis is the existence of a nearly complete Type I fimbrial gene cluster in the latter one (Additional file 3). Enterobacterial Type I fimbriae are implied to be involved in cell attachment and adhesion to surfaces leading to biofilm formation [57]. Beside being a virulence determinant the fimbriae may therefore be a tool of epiphytic bacteria for colonization and protection against environmental effects. Without production of a capsular polysaccharide by E. tasmaniensis, the fimbriae may replace the capsules 


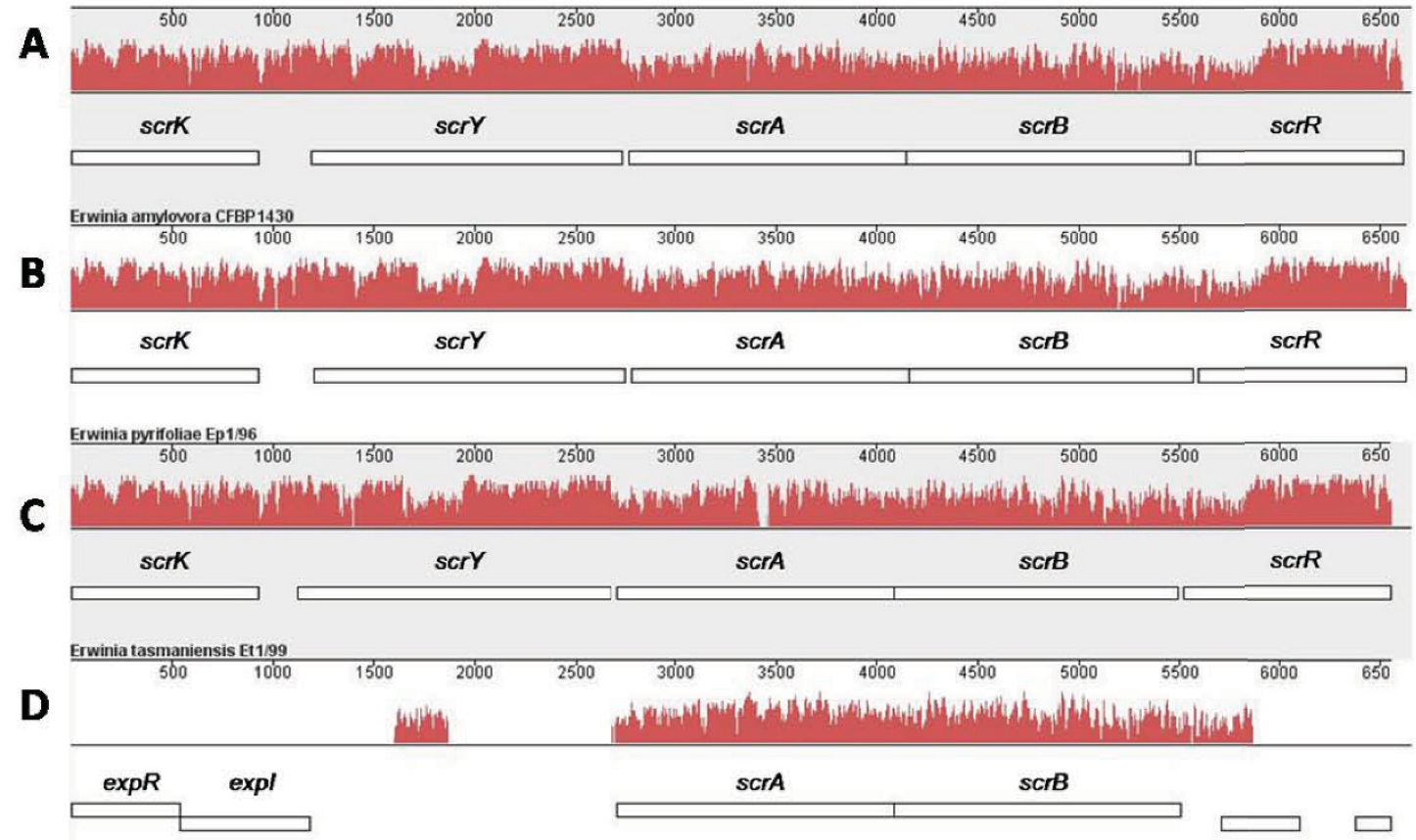

Erwinia tasmaniensis Et1/99

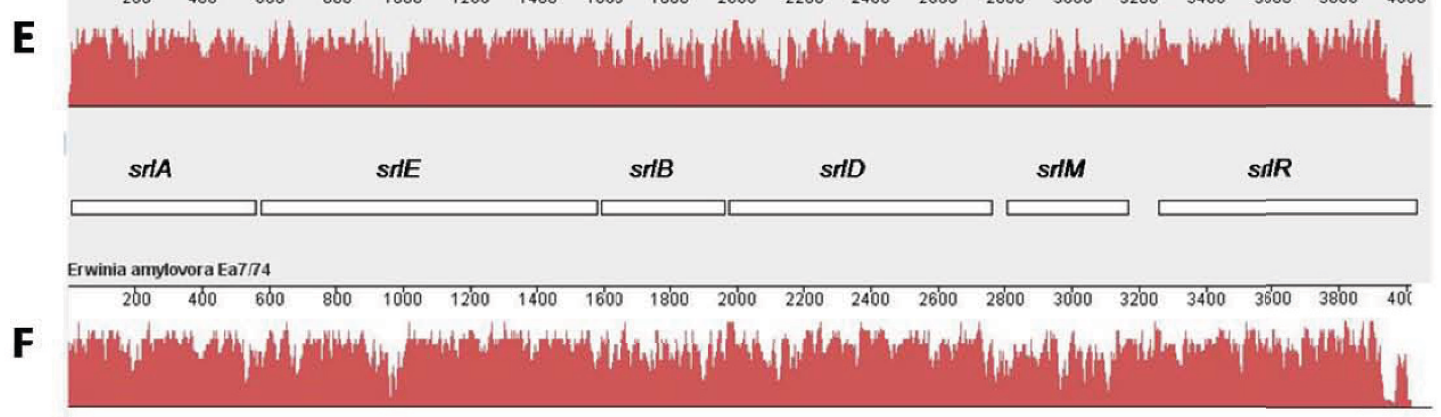

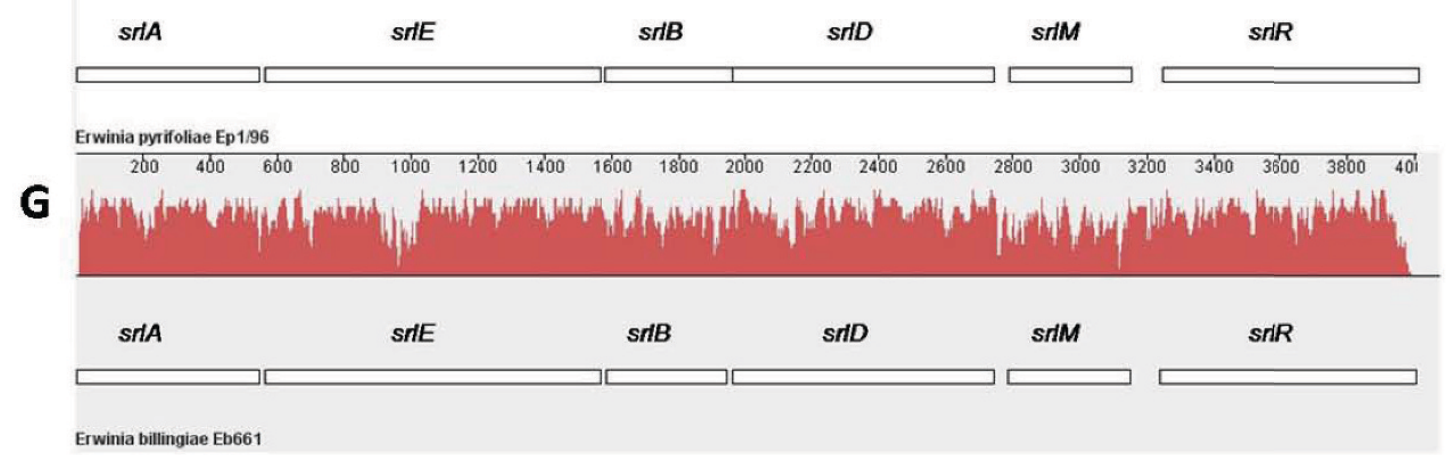

Figure 4 Alignment of the sucrose and sorbitol operons from E. amylovora, E. pyrifoliae and E. tasmaniensis with Mauve v.2.3.0. The similarity profile of the alignment in the progressive mode is shown in red [55]. The height of the bars corresponds to the average level of conservation in the sequence. White boxes indicate genes. The alignment of the sucrose operons (A-D) comprise nucleotide sequences of E. amylovora strain CFBP 1430 (A; Acc. No. AJ250722, positions 230 6950), E. pyrifoliae strain Ep1/96 (B; Acc. No. FP236842, positions 2206738- 2213359) and E. tasmaniensis strain Et1/ 99 (C; Acc. No. CU468135, positions 2119695- 2126241). The genes scrA and scrB are duplicated in the genome of E. tasmaniensis Et1/99 (D; positions 1064052- 1070604). There is a continuous homology in the sucrose operons shown in the similarity profiles. Alignment of the sorbitol operons (E-G) comprises nucleotide sequences of E. amylovora strain Ea7/74 (E; Acc. No. Y14603, positions 276- 4479), E. pyrifoliaestrain Ep1/96 (F; Acc. No. FP236842, positions 668798-672810) and E. billingiae strain Eb661 (G; Acc. No. FP236843, positions 2907872- 2911878). 
to allow bacterial aggregation [15]. This is supported by the lack of a Type I fimbrial gene cluster in E. billingiae, which produces EPS and may thus not depend on fimbriae. On the other hand, the existence of Type I fimbriae may induce plant defence responses comparable to the effect of FimH on mammalian cells [58].

While the distribution of Type I fimbriae genes seems to differ, all Erwinia species except E. billingiae possess a comparable incomplete instrumentation of K88 (F4) fimbriae genes. These fimbriae were found in enterotoxigenic $E$. coli strains and identified as virulence factors, to determine attachment to specific receptors of intestinal cells [59]. The cluster, build up with faeBCDEFGHIJ, could be reconstructed except for the regulator FaeB and the component FaeJ, without known expression and function [60]. However, a CDS coding for a possible regulatory protein was found in E. pyrifoliae instead of FaeB, leading to the assumption that functional F4 fimbriae participate in adhesion of these species. There are no hints if they are related to pathogenicity.

Another gene cluster first described in enterotoxigenic E. coli strains and also found in the erwinias forms the class 5 fimbriae with the surface antigen CS14 in the csu$A B C D E$-operon [61]. They are involved for E. coli in attachment to specific intestinal epithelial cells. Whether F4 and class 5 fimbriae have a cumulative effect by adhering to receptors of the same cells or aim at different cells and have specific functions is difficult to determine on the molecular level. Since both, pathogenic and nonpathogenic, Erwinia species possess these genes, their role in pathogenicity is unclear.

Furthermore, genes for the global regulator of fimbrial expression, the heat-stable nucleoid-structuring protein (hns), are present in the erwinias [59]. In E. amylovora, E. pyrifoliae, E. billingiae and E. tasmaniensis, copies of an $h n s$ gene are located on the chromosome and also on a plasmid. E. tasmaniensis carries two chromosomal hns genes. The global regulator also affects EPS synthesis and the protein binds to the $l s c$ promoter region of E. amylovora [62].

Strain Eb661 encodes several matrix components necessary for biofilm formation. Genes for cellulose synthesis (bsc-and bcs-operon) were identified as well as a CDS for the surface protein BapA. This instrumentation is similar to biofilm producing Salmonella species [63]. Several potential adhesion factors such as hemaglutinin-like proteins may support surface colonization [64].

The three Erwinia species share a common set of genes for proteases and siderophore production, which are important virulence factors in soft rot erwinias [65]. Two proteases $(\mathrm{Ptr} A, \mathrm{Ptr} B$ ) and siderophores (encoded by foxR, $d f o A$, alc $A$ ) may help in colonization and acquisition of nutrients $[15,66]$. Interestingly, the protease operon for the secreted enzyme PrtA, connected with virulence of $E$. amylovora, is not represented in the genomes of E. pyrifoliae, E. tasmaniensis or E. billingiae [67].

Furthermore, virulence factors such as the cytotoxic necrotizing factors Cnf1 and Cnf2 were identified. These proteins were connected with pathogenic $E$. coli strains to alter signal transduction resulting in modified cell morphology and cell cycles as well as decreased phagocytosis of the bacteria $[68,69]$. Cnf1 was shown to inhibit apoptosis, which may help bacteria to survive after cell invasion and grow in an adapted environment [70]. In the case of the Erwinia species which have been investigated, cnf1and $c n f 2$-genes could be identified in all species except $E$. billingiae, a possible role of Cnf may be to weaken defence response therefore helping the bacteria to spread. $\mathrm{Cnf}$ is thought to influence transcription factors via effects on signal transduction [71].

A striking feature of E. pyrifoliae strain Ep1/96 is the presence of an assumed non-ribosomal peptide synthetase (NRPS; suggested name EppT; EpC_11160) with a size of 7028 aa. It shows similarities to several non-ribosomal peptide synthetases (NRPSs). It shows high similarity with a protein of unknown function from Photorhabdus luminescens (syn. Xenorhabdus luminescens), an enterobacterial pathogen of insects and an NRPS of the distantly related soft rot pathogen P. atrosepticum SCRI1043 encoded in an island typical for horizontal gene transfer [39,72]. Similar NRPS proteins are also encoded in the genome of E. tasmaniensis strain Et1/99 and $E$. billingiae strain Eb661, but differ in size and domain content (Figure 5). According to a prediction program the NRPS-encoding ORF of E. pyrifoliae strain Ep1/ 96 contains six modules for the synthesis of a hexameric peptide with Ala-Thr-Thr-Gln-Phe-Ser [73]. The NRPS proteins in the genome of E. billingiae and E. tasmaniensis are considerably smaller with an encoding capacity for possible attachment of modified Leu-Leu-Xaa and Ser, respectively. No significant relation to the modules to the analogous E. pyrifoliae region can be deduced. The short NRPS-regions may only encode small modified peptides.

The presence of the eppT gene in strain Ep1/96 may be a result of an integration event as it is indicated by the phage integrase located upstream. Similar proteins could be identified in other plant pathogens such as $P$. syringae pv. syringae, which has been involved in synthesis of the phytotoxin syringomycin [74]. This list can be extended to several plant pathogens such as Ralstonia solanacearum and Xanthomonas axonopodis pv. citri, but also to the non-pathogenic species Pseudomonas fluorescens[39]. The NRPSs vary in size (e.g. 3351 aa for Et1/99 compared to 7028 aa for Ep1/96) [75]. The NRPS of $E$. pyrifoliae and the one of $P$. atrosepticum show a similar length (7028 aa/7523 aa) and nearly 6000 aa could be aligned with an identity of at least $41 \%$. 


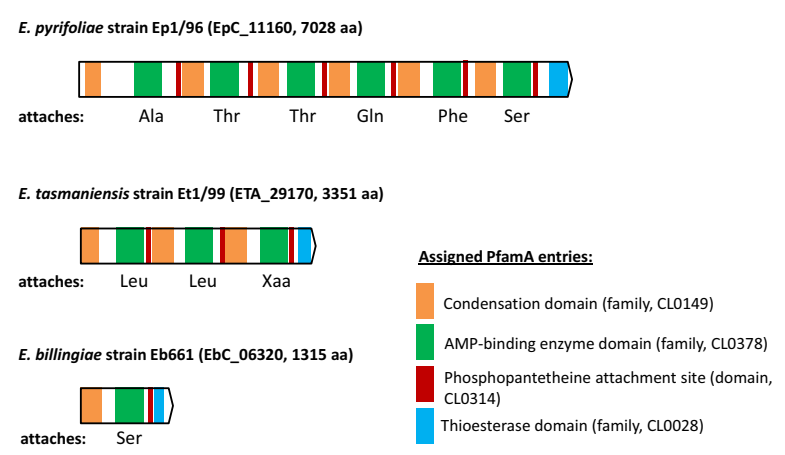

Figure 5 Analysis of NRPSs for the strains Ep1/96 (position 1,277,774-1,298,860), Et1/99 (pos. 3,243,033- 3,253,088) and Eb661 (pos. complement 749,230-753,177). Locus tag and size are given in brackets. NRPSs were identified by BLASTP and domains were assigned according to Pfam. Predicted amino acids to be synthesized are noted, if a prediction was available. Abbreviations of amino acids: Ala, Alanine; Gln, Glutamine; Leu, Leucine, Phe, Phenylalanine; Ser, Serine; Thr, Threonine.

\section{Conclusions}

The comparative analysis of E. billingiae strain Eb661, E. tasmaniensis strain Et1/99 and E. pyrifoliae strain Ep1/96 highlights the different genome organization within this genus driven by recombination events. The genomes of these epiphytic and pathogenic bacteria show high accordance of single genes and gene clusters, which are potential virulence factors in pathogenic species. The difference in lifestyle may depend on protein secretion and invasion into plants. E. billingiae lacks any T3SS in contrast to E. tasmaniensis and E. pyrifoliae. Differences between both pathogenic E. amylovora and E. pyrifoliae and the non-pathogenic E. tasmaniensis include a lack of the HAE-region in the hrp/hrc-T3SS, of the SopA and PagC proteins and the presence of a VirK protein and putatively of Type I fimbriae. E. billingiae shows much larger variations, e.g. apparently more possibilities for biofilm formation and adhesion, no synthesis or utilization of levan, the absence of a non-ribosomal peptide synthetase similar to EppT and a T3SS with the HAEregion, the SopA protein and possesses a VirK protein. Therefore, those components probably represent factors to describe pathogenic and non-pathogenic Erwinia species. Factors such as synthesis of EPS and levan, utilization of sugar and sugar alcohols as well as expression of proteases and siderophores may be related to nutrient acquisition and to modulate plant defence.

The role of the NRPS in the pathogenic strain Ep1/96 remains unclear. A phytotoxin could be an advantage in weakening the plant during the colonization and can explain differences in the habitat of Erwinia species.

Virulence for E. pyrifoliae may depend on the factors summarized in this section. Accumulation in the genome of E. pyrifoliae could be interpreted as the result of an evolutionary adaptation process resulting in the specialization as a plant pathogen. The genetic distance between the pathogenic Erwinia species and E. tasmaniensis is small, and larger to E. billingiae, which has a tendency to invade necrotic tissue of plants. Several differences in genes and their expression apparently restrict $E$. tasmaniensis to exist as an epiphyte on plant surfaces. This enables the species to survive especially on flowers and supports its potential to compete with pathogens such as E. amylovora and possibly E. pyrifoliae.

\section{Methods}

\section{Genome determination}

E. pyrifoliae strain Ep1/96 (DSM 12162) and E. billingiae strain Eb661 (DSM 17872) were cultured as described previously $[11,18]$. DNA was isolated with the Genomic DNA kit (Qiagen, Hildesheim, Germany) according to the manufacturer's instructions. The genomic sequences were determined by whole genome shotgun sequencing using Sanger based sequencing technology and pyrosequencing.

The genomes of E. pyrifoliae strain Ep1/96 and $E$. billingiae strain Eb661 were covered by short insert shotgun libraries with 1.5 and $2.5 \mathrm{~kb}$ inserts and fosmid libraries with $37 \mathrm{~kb}$ inserts (CopyControl ${ }^{\mathrm{m}}$ Fosmid Library Production Kit, Epicentre, Madison, U.S.A.) [76]. Endsequencing was performed on recombinant plasmids using BigDye 3.1 chemistry and 3730XL capillary sequencers (ABI, Darmstadt, Germany) resulting in a 9fold sequencing coverage for strain Ep1/96 and a 11-fold sequencing coverage for strain Eb661. The high number of fosmid reads $(24,252$ and 7,096) resulted in one uncovered chromosomal region for strain Ep1/96 and a complete physical coverage by fosmid clones of the chromosome of strain Eb661. To reduce finishing experiments pyrosequencing was performed using the GS20 sequencer for strain Ep1/96 and the GS FLX platform for strain Eb661 (both 454 life science/Roche) resulting in an additional 25-fold (1,043,447 reads) and 8-fold (194,142 reads) sequencing coverage, respectively.

Data assembly was performed for strain Ep1/96 within two steps. GS20 data were initially assembled by Newbler (454 life science/Roche) and the resulting contigs were fragmented using PERL scripts resulting in overlapping sequence fragments, which were assigned as forward and reverse reads in fasta format and the corresponding fasta quality files. The thus obtained faked reads were assembled together with the Sanger derived processed reads using PhredPhrap http://www.phrap.org. GS FLX data and Sanger derived reads for strain Eb661 were assembled using the Celera assembler [77]. Assembled data for both projects were imported into Consed, edited and verified. Finishing experiments were performed by primer- 
walking on bridging clones and PCR products to improve sequence quality and gap closure [78].

\section{Genome annotation and comparison}

Protein coding sequences were predicted by Glimmer3 and manually curated in Artemis $[79,80]$. Artemis was also used to calculate cumulative GC-skews [(G-C)/ $(\mathrm{G}+\mathrm{C})]$ of the chromosomes. The genome sequences were annotated with HTGA [81]. Structural rRNAs and tRNAs were determined using RNAmmer and tRNAscan-SE $[82,83]$. Integrated bacteriophages were predicted by PhageFinder [84]. Furthermore, sequence analysis was improved using the RAST analysis platform [85]. NRPSs content was subsequently analysed by Pfam http://pfam.sanger.ac.uk/ and specificity prediction (NRPSredictor, http://www-ab.informatik.uni-tuebingen.de/toolbox/) [73].

Genome comparisons were performed for E. billingiae strain Eb661 (this study), E. tasmaniensis strain Et1/99, E. pyrifoliae strain Ep1/96 (this study) and partial sequences of E. amylovora strain Ea273 [15]. The complete genome sequence of E. amylovora strain Ea273 (ATCC 49946) was published recently: FN666575, FN666576, and FN666577. Conserved synteny was examined using ACT with the big_blast.pl script (5000 bases sequence size; BLASTN algorithm) [86].

Core and pan genome for the deduced proteins were analysed by BLASTCLUST http://www.ncbi.nlm.nih.gov/ and parsed through a script to obtain intersections. Numbers were calculated using an identity of $60 \%$, an alignment length of $70 \%$ and an e-value of $1 e-6$ at least as cutoffs for these analyses. The utilized scripts were implemented in a new public web-service at http:// www.reziclust.molgen.mpg.de, which allows recalculation of results as well as performing new analyses. Results were parsed in addition through scripts for visualization of the present or absent potential orthologs within each genome.

Potential paralogs were estimated using BLAST [87]. Deduced protein sets of the chromosomes were compared against themselves and filtered with MSPcrunch using a minimal identity of $90 \%$ for this purpose [88].

\section{Data and strain access}

The annotated sequences of E. pyrifoliae strain Ep1/96 have been deposited in Genbank/EMBL/DDBJ under accession numbers FP236842 (chromosome), FP928999 (pEp2.6), FP236827 (pEP03), FP236828 (pEP05), FP236829 (pEP36), and of E. billingiae strain Eb661 under accession numbers FP236843 (chromosome), FP236826 (pEB102) and FP236830 (pEB170).

The strains used for genomic sequencing are deposited in various international strain collections: Ep1/96 as DSM 12162, CFBP 4171; Eb661 (type strain) as DSM 17872,
CFBP 6830, NCPPB 661, LMG 2613 and the previously sequenced E. tasmaniensis strain Et1/99 (type strain) as DSM 17950, CFBP 7177, NCPPB 4357, LMG 25318.

\section{Additional material}

\begin{abstract}
Additional file 1 Cumulative $\mathrm{GC}$ skew $[(\mathrm{G}-\mathrm{C}) /(\mathrm{G}+\mathrm{C})]$ of three investigated chromosomes.

Additional file $\mathbf{2}$ Chromosome maps of the three investigated species highlighting the conserved protein-coding gene content and the individual set. PDFs are of high resolution and allow enlarging regions of interest.

Additional file $3 \mathrm{Genes}$ with potential impact for virulence in pathogenic erwinias encoded in the genomes of E. pyrifoliae, E. billingiae and E. tasmaniensis

Additional file $4 \mathrm{~A}$ scheme for involvement of proteins from $E$. pyrifoliae, E. tasmaniensis and E. billingiae or in assembly of the T6SS
\end{abstract}

\section{Authors' contributions}

MK, AMM, HK, KH and RR contributed to library construction, template preparation, sequence determination and assembly. AMM, IG, FK, YM, KG and MK participated in annotation and performed sequence analysis. MK, AMM, KG and RR drafted the manuscript.

All authors read and approved the final manuscript.

\section{Acknowledgements}

We acknowledge Julia Cekanov, Janina Thiel, Bernd Timmermann and Ines Müller (Berlin) for technical assistance, and Steffen Scheer, Sven Klages and Alfred Beck (Berlin) for computational support.

\section{Author Details}

${ }^{1}$ Max Planck Institute for Molecular Genetics, htpt group, Ihnestr. 63, D-14195 Berlin, Germany, ${ }^{2}$ Julius Kuehn Institute, Institute for Plant Protection in Fruit Crops and Viticulture, Schwabenheimer Str. 101, D-69221 Dossenheim, Germany and 3Heidelberg Institute for Plant Science, Neuenheimer Feld 360, D-69120 Heidelberg, Germany

Received: 1 September 2009 Accepted: 22 June 2010

Published: 22 June 2010

\section{References}

1. Rhim SL, Volksch B, Gardan L, Paulin JP, Langlotz C, Kim WS, Geider K Erwinia pyrifoliae, an Erwinia species different from Erwinia amylovora, causes a necrotic disease of Asian pear trees. Plant Pathology 1999, 48(4):514-520.

2. Shrestha R, Koo J, Park D, Hwang I, Hur J, Lim C: Erwinia pyrifoliae, a causal endemic pathogen of shoot blight of Asian pear tree in Korea. The Plant Pathology Journal 2003, 19(6):294-300.

3. Vanneste J: Fire blight: The disease and its causative agent, Erwinia amylovora. Wallingford, Oxon, UK; New York, NY, USA: CABI Pub; 2000:370.

4. Jakovljevic V, Jock S, Du Z, Geider K: Hypersensitive response and acylhomoserine lactone production of the fire blight antagonists Erwinia tasmaniensis and Erwinia billingiae. Microbial Biotechnology 2008:416-424

5. Loper JE, Henkels MD, Roberts RG, Grove GG, Willett MJ, Smith TJ: Evaluation of Streptomycin, Oxytetracycline, and Copper Resistance of Erwinia amylovora isolated from Pear Orchards in Washington-State. Plant Disease 1991, 75(3):287-290.

6. McManus PS, Jones AL: Epidemiology and Genetic-Analysis of Streptomycin-Resistant Erwinia amylovora from Michigan and Evaluation of Oxytetracycline for Control. Phytopathology 1994, 84(6):627-633.

7. McManus PS, Stockwell VO, Sundin GW, Jones AL: Antibiotic use in plant agriculture. Annu Rev Phytopathol 2002, 40:443-465.

8. Moller WJ, Schroth MN, Thomson SV: The Scenario of Fire Blight and Streptomycin Resistance. Plant Disease 1981, 65(7):563-568. 
9. Russo NL, Burr TJ, Breth DI, Aldwinckle HS: Isolation of streptomycinresistant isolates of Erwinia amylovora in New York. Plant Disease 2008 92(5):714-718

10. Norelli $\mathrm{L}$, Jones $A L$, Aldwinckle HS: Fire blight management in the twenty-first century - Using new technologies that enhance host resistance in apple. Plant Disease 2003, 87(7):756-765.

11. Kim WS, Gardan L, Rhim SL, Geider K: Erwinia pyrifoliae sp. nov., a novel pathogen that affects Asian pear trees (Pyrus pyrifolia Nakai). Int J Syst Bacteriol 1999, 49(2):899-906.

12. Geider K, Auling G, Jakovljevic V, Volksch B: A polyphasic approach assigns the pathogenic Erwinia strains from diseased pear trees in Japan to Erwinia pyrifoliae. Lett App/ Microbio/ 2009, 48(3):324-330.

13. Aldridge $P$, Metzger M, Geider K: Genetics of sorbitol metabolism in Erwinia amylovora and its influence on bacterial virulence. Mol Gen Genet 1997, 256(6):611-619.

14. Bogs J, Geider K: Molecular analysis of sucrose metabolism of Erwinia amylovora and influence on bacterial virulence. J Bacterio/ 2000, 182(19):5351-5358.

15. Kube M, Migdoll AM, Müller I, Kuhl H, Beck A, Reinhardt R, Geider K: The genome of Erwinia tasmaniensis strain Et1/99, a non-pathogenic bacterium in the genus Erwinia. Environ Microbiol 2008, 10(9):2211-2222.

16. Geider K, Auling G, Du Z, Jakovljevic V, Jock S, Volksch B: Erwinia tasmaniensis sp. nov., a non-phytopathogenic bacterium from apple and pear trees. Int J Syst Evol Microbiol 2006, 56(12):2937-2943.

17. Billing E, Baker LAE: Characteristics of Erwinia-Like Organisms Found in Plant Material. Journal of Applied Bacteriology 1963, 26(1):58.

18. Mergaert J, Hauben L, Cnockaert MC, Swings J: Reclassification of nonpigmented Erwinia herbicola strains from trees as Erwinia billingiae sp. nov. Int J Syst Bacterio/ 1999, 49(2):377-383.

19. Steinberger $\mathrm{E}$, Beer S: Creation and complementation of pathogenicity mutants of Erwinia amylovora. Molecular plant-microbe interactions 1988, 1(3):135-144.

20. Shrestha R, Park DH, Cho JM, Cho S, Wilson C, Hwang I, Hur JH, Lim CK: Genetic organization of the hrp genes cluster in Erwinia pyrifoliae and characterization of HR active domains in HrpNEp protein by mutational analysis. Mol Cells 2008, 25(1):30-42.

21. Bugert $P$, Geider $K$ : Molecular analysis of the ams operon required for exopolysaccharide synthesis of Erwinia amylovora. Mol Microbiol 1995, 15(5):917-933.

22. Kim WS, Schollmeyer M, Nimtz M, Wray V, Geider K: Genetics of biosynthesis and structure of the capsular exopolysaccharide from the Asian pear pathogen Erwinia pyrifoliae. Microbiology 2002, 148(12):4015-4024

23. Dellagi A, Brisset MN, Paulin JP, Expert D: Dual role of desferrioxamine in Erwinia amylovora pathogenicity. Mol Plant Microbe Interact 1998, 11(8):734-742.

24. Sauer S, Freiwald A, Maier T, Kube M, Reinhardt R, Kostrzewa M, Geider K: Classification and identification of bacteria by mass spectrometry and computational analysis. PLOS One 2008, 3(7):e2843.

25. Liu SL, Sanderson KE: Homologous recombination between rrn operons rearranges the chromosome in host-specialized species of Salmonella. FEMS Microbio/ Lett 1998, 164(2):275-281

26. Falkenstein $\mathrm{H}$, Zeller W, Geider K: The $29 \mathrm{~Kb}$ Plasmid, Common in Strains of Erwinia amylovora, Modulates Development of Fireblight Symptoms. Journal of General Microbiology 1989, 135:2643-2650.

27. Mohammadi M, Moltmann E, Zeller W, Geider K: Characterisation of naturally occurring Erwinia amylovora strains lacking the common plasmid pEA29 and their detection with real-time PCR. European Journal of Plant Pathology 2009, 124(2):293-302.

28. Lamark T, Rokenes TP, McDougall J, Strom AR: The complex bet promoters of Escherichia coli: regulation by oxygen (ArCA), choline (Betl), and osmotic stress. J Bacterio/ 1996, 178(6):1655-1662.

29. Hayes F: A family of stability determinants in pathogenic bacteria. $J$ Bacteriol 1998, 180(23):6415-6418.

30. Hueck CJ: Type III protein secretion systems in bacterial pathogens of animals and plants. Microbiol Mol Biol Rev 1998, 62(2):379-433.

31. Coburn B, Sekirov I, Finlay BB: Type III secretion systems and disease. Clin Microbiol Rev 2007, 20(4):535-549.

32. McCann HC, Guttman DS: Evolution of the type III secretion system and its effectors in plant-microbe interactions. New Phytol 2008, 177(1):33-47.
33. Oh CS, Kim JF, Beer SV: The Hrp pathogenicity island of Erwinia amylovora and identification of three novel genes required for systemic infection. Molecular Plant Pathology 2005, 6(2):125-138.

34. Dale $\mathrm{C}$, Jones $\mathrm{T}$, Pontes $\mathrm{M}$ : Degenerative evolution and functional diversification of type-III secretion systems in the insect endosymbiont Sodalis glossinidius. Mol Biol Evol 2005, 22(3):758-766.

35. Osiecki JC, Barker J, Picking WL, Serfis AB, Berring E, Shah S, Harrington A Picking WD: IpaC from Shigella and SipC from Salmonella possess similar biochemical properties but are functionally distinct. $\mathrm{Mol}$ Microbiol 2001, 42(2):469-481.

36. Collazo CM, Zierler MK, Galan JE: Functional analysis of the Salmonella typhimurium invasion genes invl and inv $J$ and identification of a target of the protein secretion apparatus encoded in the inv locus. $\mathrm{Mol}$ Microbiol 1995, 15(1):25-38.

37. Zhao Y, Sundin GW, Wang D: Construction and analysis of pathogenicity island deletion mutants of Erwinia amylovora. Can J Microbiol 2009, 55(4):457-464

38. Penheiter KL, Mathur N, Giles D, Fahlen T, Jones BD: Non-invasive Salmonella typhimurium mutants are avirulent because of an inability to enter and destroy M cells of ileal Peyer's patches. Mol Microbio/ 1997, 24(4):697-709.

39. Bell KS, Sebaihia M, Pritchard L, Holden MT, Hyman LJ, Holeva MC, Thomson NR, Bentley SD, Churcher LJ, Mungall K, et al:: Genome sequence of the enterobacterial phytopathogen Erwinia carotovora subsp. atroseptica and characterization of virulence factors. Proc Natl Acad Sci USA 2004, 101(30):11105-11110.

40. Diao J, Zhang Y, Huibregtse JM, Zhou D, Chen J: Crystal structure of SopA, a Salmonella effector protein mimicking a eukaryotic ubiquitin ligase. Nat Struct Mol Biol 2008, 15(1):65-70.

41. Wood MW, Jones MA, Watson PR, Siber AM, McCormick BA, Hedges S, Rosqvist R, Wallis TS, Galyov EE: The secreted effector protein of Salmonella dublin, SopA, is translocated into eukaryotic cells and influences the induction of enteritis. Cell Microbio/ 2000, 2(4):293-303.

42. Garcia-Calderon CB, Casadesus J, Ramos-Morales F: Rcs and PhoPQ regulatory overlap in the control of Salmonella enterica virulence. $J$ Bacteriol 2007, 189(18):6635-6644

43. Detweiler CS, Monack DM, Brodsky IE, Mathew H, Falkow S: virK, somA and $r c s C$ are important for systemic Salmonella enterica serovar Typhimurium infection and cationic peptide resistance. Mol Microbiol 2003, 48(2):385-400.

44. Henderson IR, Navarro-Garcia F, Desvaux M, Fernandez RC, Ala'Aldeen D: Type $V$ protein secretion pathway: the autotransporter story. Microbiol Mol Biol Rev 2004, 68(4):692-744.

45. Pukatzki S, McAuley SB, Miyata ST: The type VI secretion system: translocation of effectors and effector-domains. Curr Opin Microbio 2009, 12(1):11-17

46. Pukatzki S, Ma AT, Sturtevant D, Krastins B, Sarracino D, Nelson WC Heidelberg JF, Mekalanos JJ: Identification of a conserved bacterial protein secretion system in Vibrio cholerae using the Dictyostelium host model system. Proc Natl Acad Sci USA 2006, 103(5):1528-1533.

47. Filloux A, Hachani A, Bleves S: The bacterial type VI secretion machine: yet another player for protein transport across membranes. Microbiology 2008, 154(6):1570-1583.

48. Shrivastava S, Mande SS: Identification and functional characterization of gene components of Type VI Secretion system in bacterial genomes. PLoS One 2008, 3(8):e2955.

49. Geider K: Structure, biosynthesis and regulation of capsular exopolysaccharide of Erwinia amylovora and other species and role in pathogenicity. Bacterial Polysaccharides, Current Innovations and future trends 2009:223-238.

50. Bellemann P, Geider K: Localization of transposon insertions in pathogenicity mutants of Erwinia amylovora and their biochemical characterization. J Gen Microbiol 1992, 138(5):931-940

51. Geier G, Geider K: Characterization and Influence on Virulence of the Levansucrase Gene from the Fireblight Pathogen Erwinia amylovora. Physiological and Molecular Plant Pathology 1993, 42(6):387-404

52. Geider K: Exopolysaccharides of Erwinia amylovora: structure, biosynthesis, regulation, role in pathogenicity of amylovoran and levan. In Fire Blight: The Disease and its Causative Agent, Erwinia amylovora Wallingford, Oxon/UK.- New York, NY, USA: CABI Pub.; 2000:117-140. 
53. Wanker E, Huber A, Schwab H: Purification and characterization of the Bacillus subtilis levanase produced in Escherichia coli. Appl Environ Microbiol 1995, 61(5):1953-1958.

54. Suleman P, Steiner P: Relationship between sorbitol and solute potential in apple shoots relative to fire blight symptom development after infection by Erwinia amylovora. Phytopathology (USA) 1994:1244-1250.

55. Darling AC, Mau B, Blattner FR, Perna NT: Mauve: multiple alignment of conserved genomic sequence with rearrangements. Genome Res 2004, 14(7):1394-1403.

56. Zabner J, Seiler MP, Launspach JL, Karp PH, Kearney WR, Look DC, Smith JJ, Welsh MJ: The osmolyte xylitol reduces the salt concentration of airway surface liquid and may enhance bacterial killing. Proc Natl Acad Sci USA 2000, 97(21):11614-11619.

57. Blumer C, Kleefeld A, Lehnen D, Heintz M, Dobrindt U, Nagy G, Michaelis K, Emody L, Polen T, Rachel R, et al.: Regulation of type 1 fimbriae synthesis and biofilm formation by the transcriptional regulator LrhA of Escherichia coli. Microbiology 2005, 151(10):3287-3298.

58. Ashkar AA, Mossman KL, Coombes BK, Gyles CL, Mackenzie R: FimH adhesin of type 1 fimbriae is a potent inducer of innate antimicrobial responses which requires TLR4 and type 1 interferon signalling. PLOS Pathog 2008, 4(12):e1000233.

59. Edwards RA, Puente JL: Fimbrial expression in enteric bacteria: a critical step in intestinal pathogenesis. Trends Microbio/ 1998, 6(7):282-287.

60. Bakker D, Willemsen PT, Willems RH, Huisman TT, Mooi FR, Oudega B, Stegehuis F, de Graaf FK: Identification of minor fimbrial subunits involved in biosynthesis of K88 fimbriae. J Bacteriol 1992, 174(20):6350-6358.

61. Anantha RP, McVeigh AL, Lee LH, Agnew MK, Cassels FJ, Scott DA, Whittam TS, Savarino SJ: Evolutionary and functional relationships of colonization factor antigen $\mathrm{i}$ and other class 5 adhesive fimbriae of enterotoxigenic Escherichia coli. Infect Immun 2004, 72(12):7190-7201.

62. Hildebrand $M$, Aldridge $P$, Geider $K$ : Characterization of $h n s$ genes from Erwinia amylovora. Mol Genet Genomics 2006, 275(3):310-319.

63. Jonas K, Tomenius H, Kader A, Normark S, Romling U, Belova LM, Melefors $\mathrm{O}$ : Roles of curli, cellulose and BapA in Salmonella biofilm morphology studied by atomic force microscopy. BMC Microbio/ 2007, 7:70.

64. Gottig N, Garavaglia BS, Garofalo CG, Orellano EG, Ottado J: A filamentous hemagglutinin-like protein of Xanthomonas axonopodis pv. citri, the phytopathogen responsible for citrus canker, is involved in bacterial virulence. PLoS One 2009, 4(2):e4358.

65. Toth IK, Pritchard L, Birch PR: Comparative genomics reveals what makes an enterobacterial plant pathogen. Annu Rev Phytopathol 2006, 44:305-336.

66. Oh CS, Beer SV: Molecular genetics of Erwinia amylovora involved in the development of fire blight. FEMS Microbiol Lett 2005, 253(2):185-192.

67. Zhang Y, Bak DD, Heid H, Geider K: Molecular characterization of a protease secreted by Erwinia amylovora. J Mol Biol 1999, 289(5):1239-1251.

68. Hofman P, Le Negrate G, Mograbi B, Hofman V, Brest P, Alliana-Schmid A, Flatau G, Boquet P, Rossi B: Escherichia coli cytotoxic necrotizing factor-1 (CNF-1) increases the adherence to epithelia and the oxidative burst of human polymorphonuclear leukocytes but decreases bacteria phagocytosis. J Leukoc Biol 2000, 68(4):522-528.

69. Rippere-Lampe KE, O'Brien AD, Conran R, Lockman HA: Mutation of the gene encoding cytotoxic necrotizing factor type $1(\mathrm{cnf}(1))$ attenuates the virulence of uropathogenic Escherichia coli. Infect Immun 2001, 69(6):3954-3964.

70. Fiorentini C, Gauthier M, Donelli G, Boquet P: Bacterial toxins and the Rho GTP-binding protein: what microbes teach us about cell regulation. Cell Death Differ 1998, 5(9):720-728.

71. Fiorentini C, Falzano L, Travaglione S, Fabbri A: Hijacking Rho GTPases by protein toxins and apoptosis: molecular strategies of pathogenic bacteria. Cell Death Differ 2003, 10(2):147-152.

72. Duchaud E, Rusniok C, Frangeul L, Buchrieser C, Givaudan A, Taourit S, Bocs S, Boursaux-Eude C, Chandler M, Charles JF, et al:: The genome sequence of the entomopathogenic bacterium Photorhabdus luminescens. Nat Biotechnol 2003, 21(11):1307-1313.

73. Rausch C, Weber T, Kohlbacher O, Wohlleben W, Huson DH: Specificity prediction of adenylation domains in nonribosomal peptide synthetases (NRPS) using transductive support vector machines (TSVMs). Nucleic Acids Res 2005, 33(18):5799-5808.
74. Bender CL, Alarcon-Chaidez F, Gross DC: Pseudomonas syringae phytotoxins: mode of action, regulation, and biosynthesis by peptide and polyketide synthetases. Microbio/ Mol Biol Rev 1999, 63(2):266-292.

75. Smith DJ, Earl AJ, Turner G: The multifunctional peptide synthetase performing the first step of penicillin biosynthesis in Penicillium chrysogenum is a 421,073 dalton protein similar to Bacillus brevis peptide antibiotic synthetases. EMBO J 1990, 9(9):2743-2750.

76. Kube M, Beck A, Zinder SH, Kuhl H, Reinhardt R, Adrian L: Genome sequence of the chlorinated compound-respiring bacterium Dehalococcoides species strain CBDB1. Nat Biotechnol 2005, 23(10):1269-1273.

77. Myers EW, Sutton GG, Delcher AL, Dew IM, Fasulo DP, Flanigan MJ, Kravitz SA, Mobarry CM, Reinert KH, Remington KA, et al:: A whole-genome assembly of Drosophila. Science 2000, 287(5461):2196-2204.

78. Gordon D: Viewing and editing assembled sequences using Consed. Curr Protoc Bioinformatics 2003, Chapter 11(Unit 11 12):

79. Delcher AL, Harmon D, Kasif S, White O, Salzberg SL: Improved microbial gene identification with GLIMMER. Nucleic Acids Res 1999 , 27(23):4636-4641

80. Rutherford K, Parkhill J, Crook J, Horsnell T, Rice P, Rajandream MA, Barrell B: Artemis: sequence visualization and annotation. Bioinformatics 2000, 16(10):944-945

81. Rabus R, Kube M, Beck A, Widdel F, Reinhardt R: Genes involved in the anaerobic degradation of ethylbenzene in a denitrifying bacterium, strain EbN1. Arch Microbiol 2002, 178(6):506-516.

82. Lagesen $\mathrm{K}$, Hallin P, Rodland EA, Staerfeldt HH, Rognes T, Ussery DW: RNAmmer: consistent and rapid annotation of ribosomal RNA genes. Nucleic Acids Res 2007, 35(9):3100-3108.

83. Lowe TM, Eddy SR: tRNAscan-SE: a program for improved detection of transfer RNA genes in genomic sequence. Nucleic Acids Res 1997, 25(5):955-964.

84. Bose M, Barber RD: Prophage Finder: a prophage loci prediction tool for prokaryotic genome sequences. In Silico Biol 2006, 6(3):223-227.

85. Overbeek R, Begley T, Butler RM, Choudhuri JV, Chuang HY, Cohoon M, de Crecy-Lagard V, Diaz N, Disz T, Edwards R, et al:: The subsystems approach to genome annotation and its use in the project to annotate 1000 genomes. Nucleic Acids Res 2005, 33(17):5691-5702.

86. Carver TJ, Rutherford KM, Berriman M, Rajandream MA, Barrell BG, Parkhill J: ACT: the Artemis Comparison Tool. Bioinformatics 2005, 21(16):3422-3423.

87. Altschul SF, Madden TL, Schaffer AA, Zhang J, Zhang Z, Miller W, Lipman DJ: Gapped BLAST and PSI-BLAST: a new generation of protein database search programs. Nucleic Acids Res 1997, 25:(17):3389-3402

88. Sonnhammer EL, Durbin R: A workbench for large-scale sequence homology analysis. Comput App/ Biosci 1994, 10(3):301-307.

89. Maxson-Stein K, McGhee GC, Smith JJ, Jones AL, Sundin GW: Genetic Analysis of a Pathogenic Erwinia sp. Isolated from Pear in Japan. Phytopathology 2003, 93(11):1393-1399.

doi: 10.1186/1471-2164-11-393

Cite this article as: Kube et al., Genome comparison of the epiphytic bacteria Erwinia billingiae and E. tasmaniensis with the pear pathogen E. pyrifoliae BMC Genomics 2010, 11:393

\section{Submit your next manuscript to BioMed Central and take full advantage of:}

- Convenient online submission

- Thorough peer review

- No space constraints or color figure charges

- Immediate publication on acceptance

- Inclusion in PubMed, CAS, Scopus and Google Scholar

- Research which is freely available for redistribution 